International Journal of Child, Youth and Family Studies (2013) 2: 245-258

\title{
SELF-TREATMENT VS. RECREATIONAL MOTIVES: DIFFERENTIATING NONMEDICAL USE OF PRESCRIPTION DRUGS AMONG YOUTH
}

\section{Whitney D. Gunter, Erin J. Farley, and Daniel J. O’Connell}

\begin{abstract}
Nonmedical use of prescription drugs has become a serious social problem among American youth. Two general categories of motives for the nonmedical use of prescription drugs include self-treatment and recreational use. This study assesses differences between nonmedical prescription drug users based on their self-reported motivation for using prescription drugs. Data come from more than 11,000 11th grade students in Delaware public schools. Analyses indicate significant differences in prevalence, correlates, and consequences on nonmedical use of prescription drugs based on motivation for use. Analyses reveal that, among those students who reported nonmedical use of prescription drugs, those who are using for recreational purposes are significantly more likely to engage in other risk behaviors, such as using other illicit substances and engaging in violent behavior.
\end{abstract}

Keywords: prescription drug abuse, self-treatment, substance use

Note: The data used in this research were collected by the University of Delaware Center for Drug and Alcohol Studies as part of a study supported by the Delaware Health Fund and by the Division of Substance Abuse and Mental Health, Delaware Health and Social Services. The views and conclusions expressed in this manuscript are those of the authors and do not necessarily represent those of the University of Delaware or the sponsoring agencies.

Whitney D. Gunter, Ph.D. (the Corresponding Author) is an Assistant Professor of Sociology at Western Michigan University, 1903 West Michigan Avenue, Kalamazoo, Michigan 49008-5257, U.S.A. E-mail: whitney.gunter@wmich.edu

Erin J. Farley, Ph.D. is a Senior Research Associate at the Center for Court Innovation, 520 8th Avenue, 18th Floor, New York, New York 10018, U.S.A. E-mail: efarley@courts.state.ny.us

Daniel J. O'Connell, Ph.D. is a Scientist at the University of Delaware Center for Drug and Alcohol Studies, 257 E Main St., Suite 110, Newark, Delaware 19716, U.S.A.

E-mail: oconnell@udel.edu 
International Journal of Child, Youth and Family Studies (2013) 2: 245-258

Nonmedical prescription drug use (NMPDU) is recognized as a serious social problem among youth and young adults in the United States. Substance use data collected by Monitoring the Future (MTF), a national surveillance survey, provides relevant information on trends and current prevalence rates of substance use among youth and young adults. MTF tracks four general categories of prescription drugs for nonmedical use (stimulants, pain relievers, tranquilizers, and sedatives). According to MTF trend data reports, past-year use of nonprescribed prescription drugs among American 12th grade students has remained quite stable since 2007 (Johnston, O'Malley, Bachman \& Schulenberg, 2011). In 2011, 15 percent of 12th grade students reported having used a prescription drug without a prescription in the past year, while 22 percent reported having done so at some point in their lives (Johnston et al., 2011).

While it is somewhat reassuring to witness a stabilization in youth abuse of these categories of prescription drugs, emergency department admissions reporting the nonmedical use of prescription drugs is a serious reminder that the negative consequences remain a serious problem. According to the Drug Awareness Warning Network, emergency department admissions involving pharmaceutical use (includes prescription medicine, over the counter or dietary supplement) has increased from 2004 to 2008, increasing by 81 percent to nearly a million visits per year (Substance Abuse and Mental Health Services Administration [SAMHSA], 2011).

Despite these alarming statistics, however, there exists only a small body of research from which to understand this type of substance user and that, in turn, limits the ability to propose effective policy recommendations. The objective of the research study is to examine NMPDU among youth by utilizing a large sample of 11th grade students. These data are utilized to examine key questions regarding the nonmedical use of prescription drugs, including a focus on gender differences and the relationships between motivation, source of prescription drugs, other drug use, and non-violent and violent deviance.

\section{Youth Prescription Drug Abuse}

\section{Sources}

As NMPDU among youth began to attract greater attention, both from media and researchers, attention has been directed at discovering the source of prescription drugs for nonmedical use. Prior research focusing on the nonmedical use of stimulants has demonstrated that diversion is a major method access, with students giving, trading, or selling their prescribed drugs to other students (McCabe, Teter, \& Boyd, 2004; Poulin, 2001). It is not surprising that researchers have found that as prescription rates increase, so too does the rate of nonmedical use (Zacny et al., 2003).

Few studies have examined the sources of prescription drugs among youth. The extant research has found adolescent users largely rely on friends and family as a source for nonmedical prescription drugs (Boyd, McCabe, \& Teter, 2006; Levine \& Coupey, 2009; Schepis \& Krishnan-Sarin, 2009). Buying or stealing drugs, using a drug dealer, and relying on one's own prescribed medication were other notable sources for NMPDU (Levine \& Coupey, 2009; Schepis \& Krishnan-Sarin, 2009). 
International Journal of Child, Youth and Family Studies (2013) 2: 245-258

\section{Motivations}

Existing research has largely compared non-users, prescribed users, nonmedical users, and those who report both prescribed and nonmedical use (combined use). Examining the research findings regarding these categories of prescription drug use, one can confidently state that the nonmedical use of prescription drugs is significantly associated with other substance use. Significant associations have been found between NMPDU and cigarette use, alcohol use, binge drinking, marijuana use, cocaine, LSD, other psychedelic drugs, barbiturates, tranquilizers, heroin, and other illegal drug constructs (Boyd, McCabe, \& Teter, 2006; Herman-Stahl, Krebs, Kroutil, \& Heller, 2006; McCabe, Boyd, \& Teter, 2005; McCabe, Boyd, \& Young, 2007; McCabe et al., 2004).

After determining that nonmedical usage of prescription drugs is a significant risk factor for other substance use, the looming question to ask is why this connection exists. What are the purposes of misusing prescription drugs among American youth? As one might expect, the motivations can and often do vary based on the original purpose of the drug. Studies have found, for example, that certain motivations are tied to a particular type of prescription drug, such as using sedatives without a doctor's prescription to help fall asleep or using stimulants without a doctor's prescription to help concentrate (Boyd, McCabe, Cranford, \& Young, 2006; Boyd, Young, Grey, \& McCabe, 2009).

Despite a logical and sometime observed difference in motivations for use, only a small portion of the studies examining NMPDU account for different motivations for use when examining correlates and consequences of prescription drug abuse. Prior examination of motivations typically separated nonmedical prescription drug users into two categories: recreational users (i.e., use to get high), and self-treaters (i.e., use to treat pain). Studies have also accounted for users of prescribed medications and those who engage in NMPDU for both reasons. Notably, this research has found that recreational users (also referred to as sensation seekers) were significantly more likely than self-treaters to report alcohol, marijuana, and other drug use (Boyd, McCabe, Cranford, \& Young, 2006; Boyd et al., 2009). In addition, a recent study examining the sources of prescription drugs for recreational use among rural adolescents also found a very strong relationship between use for recreational reasons and the use of tobacco, alcohol, and marijuana (Levine \& Coupey, 2009).

\section{Consequences}

Research has also demonstrated a significant relationship between NMPDU and various problem behaviors or risk and protective factors. Focusing on delinquent behaviors and risky behaviors, research by McCabe and colleagues (2005) found high school seniors who reported the nonmedical use of pain relievers in the past year were more likely to report skipping at least one day of school in the past month, getting suspended or expelled, attending a party at least once a week, buying illegal drugs at school, as well as reporting that most or all of their friends smoke marijuana. Work by Boyd and colleagues (2009) also revealed sensation seekers were more likely to gamble and report sexual activity than self-treaters, prescribed medical users, and non-users. 
International Journal of Child, Youth and Family Studies (2013) 2: 245-258

\section{Gender Differences}

Research has found a number of significant differences by gender. Though some research has found females are more likely to report higher rates of nonmedical use of opioids (e.g., Boyd, McCabe, \& Teter, 2006), other studies have higher reports among males (e.g., McCabe et al., 2005). One of the more consistent findings is the higher rate of prescribed medical use, nonmedical use, and combined use of stimulants among males (McCabe et al., 2004). Gender differences have also been found in regard to motivations. Females are more likely to report selftreatment and males more likely to report recreational use and addiction as motivations for the nonmedical use of prescription drugs (Boyd, McCabe, \& Teter, 2006; Boyd et al., 2009). In addition, males were more likely to purchase nonmedical prescription drugs or acquire them from a physician while females were more likely to report stealing medications or getting them for free (Boyd, McCabe, \& Teter, 2006; Schepis \& Krishnan-Sarin, 2009).

\section{The Current Study}

While the current body of research improves our understanding of NMPDU among adolescents, the patterns between NMPDU, demographic variables, and various risk factors still need to be better understood. Prior research has a number of limitations that include focusing on one single type of prescription drug, analyzing data with small sample sizes, and using one general category for NMPDU. Comparisons between non-users, prescribed medical users, and nonmedical users have significantly contributed to understanding the current state of NMPDU. However, additional research has demonstrated that there are significant differences among users who are subsumed under the nonmedical category.

Some pressing issues remain regarding NMPDU among youth, including:

1. the source of these drugs, where users gain access to them;

2. the reasons some youth misuse prescription drugs, their motivations; and

3. with respect to substance use and deviance, the risk or protective factors associated with the nonmedical use of prescription drugs.

The current study attempts to address these various issues, utilizing a large sample of American 11th grade students to examine the relationships between gender and motivational differences, and their association with prescription type, source, deviant behaviors (both nonviolent and violent) and consequences with regard to the education and legal systems.

\section{Data and Methodology}

The data used in this study come from the Delaware School Survey (DSS), which is administered annually by the University of Delaware Center for Drug and Alcohol Studies to students in all Delaware public and public-charter schools. This study uses data from 11th grade students in 2006 and 2008. These years were selected because they include questions about motivations for using prescription drugs. In both years, a census of 11th grade students was attempted. Some classrooms (fewer than 15\%) were randomly selected to participate in a 
International Journal of Child, Youth and Family Studies (2013) 2: 245-258

different survey instead, and were excluded from the sample. Otherwise, classrooms were surveyed in a method designed to survey all 11th grade students present and willing to participate. In 2006, 5,728 11th grade students were present on the day when their school was surveyed. Fewer than $2 \%$ of students chose not to participate or were asked not to participate by their parents, resulting in a total sample of 5,636 students. In 2008, 5,891 11th grade students were present and fewer than 3\% chose not to participate or were asked not to participate by their parents, resulting in a total sample of 5,757 students. Combined, the two years provide a sample of 11,393 11th grade students, representing approximately $98 \%$ of students present when the classrooms were surveyed. Overall, the sample is 51\% female and $49 \%$ male. With regard to race, the sample is 57\% non-Hispanic White, 26\% non-Hispanic Black, 8\% Hispanic, and 9\% other or mixed.

\section{Measures}

The nonmedical use of prescription drugs was assessed by identifying participants who reported using at least one prescription drug without a prescription in the past year. This measure was created using questions that ask about the non-prescription use of three types of prescription drugs, including: (a) sedatives/tranquilizers (“downers, tranqs, barbs, Xanax to get high”); (b) pain relievers (“painkillers, OxyContin, codeine, Percocet, Tylenol III to get high”); and (c) stimulants ("Ritalin, Adderall, Strattera, Cylert, or Concerta without a prescription”); also in 2008 only, ("prescription uppers, diet pills, etc. to get high") and specific drugs (OxyContin, Codeine, Tylenol with codeine, Percocet, Percodan, Vicodin, Darvon, Darvacet, Endocet, Xanax, Somas, Ritalin, Adderall, Strattera, Albuterol, other asthma medication, or other prescription drug not prescribed). After filtering for only those participants who responded positively to at least one of these categories or drugs for past year usage (as well as providing a motivation for use, as discussed below), the sample was reduced to 2,254 participants. This reduced sample is used in all analyses, except when a comparison is made to the general population.

Motivations for nonmedical usage of prescription drugs were measured using the following item: "For the times when you have used prescription drugs without a prescription, please indicate how often you used them for each reason listed below”. Response options included: to relieve pain; to treat infection, allergies, illness; to have fun or get high; to add muscle, strength, endurance; to increase concentration; to relieve depression/anxiety; and to lose weight. For the analyses performed in this study, these variables have each been recoded as dichotomous indicators for past year use for each reason (e.g., used to relieve pain in the past year).

These variables were further recoded into mutually exclusive categories of self-treatment only (combining pain relief and treating infections/allergies/illness), recreational use only (to get high), both self-treatment and recreational use (multi-purpose use), and neither category. This particular definition of self-treatment use refers only to the treatment of physical ailments (e.g., use to relieve pain). Because the emphasis of this study is on comparing self-treatment use versus recreational use, most analyses will exclude cases that reported neither self-treatment nor recreational use. ${ }^{1}$

\footnotetext{
${ }^{1}$ These "other purpose" users accounted for $21.7 \%$ of users and included a variety of other motivations, including using prescription drugs for mental health, increasing concentration, weight loss, and increasing muscle. These
} 
Several variables directly related to the nonmedical use of prescription drugs will be examined, including the specific prescription drugs being used and the source for obtaining drugs without a prescription. The measures for which drugs are being used are based on the same categories and drugs used in filtering the sample to include only the nonmedical prescription drug users, which includes prescription painkillers, ADHD medication, downers, and prescription uppers. To determine the source of the drugs, participants were asked this hypothetical question: "If you wanted to get prescription drugs without a prescription, where would you get them? (Mark all that apply)". This question was asked as a hypothetical so as to allow relevance for non-users. Here, however, the sample is filtered to include only users, and therefore should act as a proxy for their actual source. The sources provided in both years included: "From my friends or other kids I know without paying for them"; "From my parents or other adults (with their permission)"; "Sneak them from my parents or other adults (without them knowing)”; “As part of a rave or party”; "From an Internet site”. Both years also included a drug dealer option, but in 2008 it was split to separate adult dealers from other children selling or sharing. For this reason, the following categories come only from the 2008 sample: "From someone under age 21 who sells them" and "From someone over age 21 who sells them".

Other substance use was measured by asking about past year cigarette, alcohol, marijuana, over-the-counter (drugs to get high), hallucinogen, inhalant, cocaine/crack, street upper, ecstasy, and heroin use. Past year delinquency was measured by asking students how often they: carry a weapon other than a gun, take some kind of weapon to school or to a school event, take part in a fight where a group of your friends are against another group, hit someone with the intention of hurting them, cheat on a test, steal something from a store without paying for it, and damage or destroy property that does not belong to you. Additional exploratory variables were measured by asking how often the participant: skips or misses classes (not the whole school day) without permission, gets suspended or expelled from school, participates in a gang or gang activities, and gets arrested. Responses were measured with a multiple point scale and recoded into dichotomous variables indicating simply whether or not the respondent participated in a particular behavior in the past year.

\section{Analytic Strategy}

The purpose of this research is to provide a descriptive comparison between nonprescribed medical and recreational users of prescription drugs. Therefore, the analyses conducted are bivariate in nature and use chi-square tests to determine significant differences. As will be more fully discussed with the results, there are significant gender differences among the motivations for using prescription drugs. Because boys and girls engage in risk behaviors to differing degrees, this may bias comparisons because motivations also differ by gender. In order to eliminate this bias, as well as other potential gender differences, analyses will be performed separately for male and female participants.

categories of purposes appeared less frequently than recreational and self-treating purposes (see Table 1). To maintain focus and provide richer specificity, the analysis of these "other purpose" cases, which would require additional or alternative analyses, are beyond the scope of this study. 
International Journal of Child, Youth and Family Studies (2013) 2: 245-258

The analyses will begin with an examination of motivation type, as well comparisons by gender. Next, further analyses will consider the context of the non-prescribed prescription drug use with respect to which types of drugs participants are using based on their motivation, as well as examining how the motivation is related to the source of the drug. Finally, analyses will be presented that explore potential correlates between risk behaviors and prescription drug use, and how this relationship is affected by motivation.

\section{Results}

The results for the gendered analyses of motivation for use are presented in Table 1. For both males and females, the three most prevalent motivations for use were relieving pain, getting high, and treating infection. Within these three most common categories, several significant gender differences do emerge. Specifically, prescription drug using males are significantly more likely than using females to use prescription drugs to get high, while females are significantly more likely to use them to relieve pain. The third most common category, treating infection, had roughly equal male and female prevalence. Gender differences also emerge in less common categories, with males significantly more likely to use prescription drugs for adding strength and increasing concentration and females more likely to use them for treating depression or for losing weight.

Table 1: Self-reported motivations for using prescription drugs by gender (percentages)

\begin{tabular}{lccc}
\hline & $\begin{array}{c}\text { Males } \\
(n=1008)\end{array}$ & $\begin{array}{c}\text { Females } \\
(n=1216)\end{array}$ & Total \\
\hline & & & \\
Relieve pain & 54.5 & 59.3 & $57.1^{*}$ \\
Treat infection, allergies, illness & 34.1 & 37.3 & 35.9 \\
Have fun or get high & 55.3 & 48.2 & $51.4^{* *}$ \\
Add muscle, strength, endurance & 11.6 & 4.0 & $7.4^{* *}$ \\
Increase concentration & 26.3 & 21.8 & $23.8^{*}$ \\
Relieve depression/anxiety & 15.4 & 22.8 & $19.5^{* *}$ \\
Lose weight & 6.3 & 12.7 & $9.8^{* *}$ \\
& & & \\
Condensed Categories: & & & \\
$\quad$ Self-Treatment & 24.5 & 32.6 & $28.9^{* *}$ \\
$\quad$ Recreational & 19.0 & 16.9 & 17.9 \\
Combined & 33.7 & 29.7 & $31.5^{*}$ \\
$\quad$ Other Purpose & 22.7 & 20.9 & 21.7 \\
& & & \\
\hline$*$ p $<.05$ & & & \\
$* *$ p $<01$ & & &
\end{tabular}

As previously discussed, these categories were then merged into mutually exclusive categories for further analysis. This is necessary because participants were asked to mark all motivations that apply, which they appeared to have done with an average of two motivations per 
respondent (the sum of all categories equal 205\%). Reducing these into mutually exclusive categories removes this large amount of overlap in the groups. The most prevalent category is both medical and recreational use, with males significantly more likely to identify with this multi-purpose subgroup. The second most common category is medical only, with a significantly higher proportion of female users in this subgroup. The next most common motivation was for neither medical nor recreational use, and the least common motivation was purely for getting high.

The analyses of drug use and source by motivation are presented in Table 2. For the prescription drug of choice, users with medical, recreation, and both motivations mostly appear to use painkillers. Recreational and multi-purpose users were significantly more likely to use prescription painkillers in comparison to those using for purely medical reasons, yet all three groups were very likely to be using painkillers as at least one of the prescription drugs being used. Other categories of drugs, including ADHD medication, downers, and prescription uppers, were less common. As with painkillers, however, individuals using for recreational or multipurpose use were significantly more likely to report use for each of these other categories. Moreover, the gap between medical only and other types of users becomes wider for these less common drug categories, with recreational and multi-purpose users between two and four times as likely to use in comparison to medical only users. These differences between motivations are evident for both males and females alike.

Table 2: Type of Rx use and source of Rx by motivation and gender (percentages)

\begin{tabular}{|c|c|c|c|c|c|c|}
\hline & \multicolumn{3}{|c|}{ Males } & \multicolumn{3}{|c|}{ Females } \\
\hline & $\begin{array}{c}\text { Self- } \\
\text { Treatment } \\
(n=247)\end{array}$ & $\begin{array}{c}\text { Recreation } \\
(n=192)\end{array}$ & $\begin{array}{l}\text { Multi- } \\
\text { Purpose } \\
(n=340)\end{array}$ & $\begin{array}{c}\text { Self- } \\
\text { Treatment } \\
(n=396)\end{array}$ & $\begin{array}{c}\text { Recreation } \\
(n=205)\end{array}$ & $\begin{array}{l}\text { Multi- } \\
\text { Purpose } \\
(n=361)\end{array}$ \\
\hline \multicolumn{7}{|l|}{ What they use: } \\
\hline Rx Painkillers & $75.3^{\mathrm{RM}}$ & $85.3^{\mathrm{SM}}$ & $91.7^{\mathrm{S}}$ & $75.5^{\mathrm{M}}$ & $71.7^{\mathrm{M}}$ & $92.5^{\mathrm{S}}$ \\
\hline ADHD Medication & $24.9^{\mathrm{RM}}$ & $49.5^{\mathrm{S}}$ & $50.0^{\mathrm{S}}$ & $19.1^{\mathrm{RM}}$ & $54.9^{\mathrm{SM}}$ & $42.8^{\mathrm{S}}$ \\
\hline Rx Uppers & $4.4^{\mathrm{RM}}$ & $12.9^{\mathrm{S}}$ & $17.0^{\mathrm{S}}$ & $3.4^{\mathrm{RM}}$ & $13.9^{\mathrm{S}}$ & $17.5^{\mathrm{S}}$ \\
\hline \multicolumn{7}{|l|}{ Where they get them: } \\
\hline Friends & $40.1^{\mathrm{RM}}$ & $64.6^{\mathrm{S}}$ & $60.7^{\mathrm{S}}$ & $45.7^{\mathrm{RM}}$ & $78.5^{\mathrm{S}}$ & $71.3^{\mathrm{S}}$ \\
\hline Parents with permission & $26.7^{\mathrm{RM}}$ & $3.6^{\mathrm{SM}}$ & $8.6^{\mathrm{S}}$ & $40.2^{\mathrm{RM}}$ & $5.9^{\mathrm{SM}}$ & $15.6^{\mathrm{S}}$ \\
\hline Parents without permission & 16.2 & 21.4 & 20.2 & $19.2^{\mathrm{M}}$ & $23.9^{\mathrm{M}}$ & $35.7^{\mathrm{S}}$ \\
\hline Dealer over age 21 & $13.9^{\mathrm{RM}}$ & $33.3^{S}$ & $42.2^{\mathrm{S}}$ & $17.5^{\mathrm{RM}}$ & $36.3^{S}$ & $17.5^{\mathrm{S}}$ \\
\hline
\end{tabular}

\footnotetext{
${ }^{S}$ Significantly different from self-treatment users $(\mathrm{p}<.05)$

${ }^{\mathrm{R}}$ Significantly different from recreational users $(\mathrm{p}<.05)$

${ }^{\mathrm{M}}$ Significantly different from multi-purpose users $(\mathrm{p}<.05)$
} 
With regard to the source of prescription drugs, there is substantial variation based on the different motivations for use. Specifically, those using for medical purposes are significantly less likely to be getting the drugs from friends, at a party, or from a dealer. They are also less likely to get them from a parent without permission, though that difference is only significant for females, which is largely driven by female multi-purpose users being much more likely to be taking drugs from parents without permission. Conversely, medical only users are significantly and dramatically more likely to be getting the drugs from their parents with permission. In comparison to recreational users, male medical users are more than seven times as likely to be getting the drugs from their parents, and female medical users are more than six times as likely to have parents as their supplier. The proportions of multi-purpose users getting drugs from their parents are between these two extremes for both genders, and only significantly different from medical users indicating more similarity to recreational users. Finally, very few users report getting their non-prescribed prescription drugs over the Internet, with no significant differences found.

The final set of analyses, examining risk behaviors and other deviant behaviors by motivation, is presented in Table 3. As a reference for what constitutes normal prevalence, the overall percent of 11th grade students engaging in each behavior is also presented, but is not included in the statistical analyses for significance. For substance use, multi-purpose and recreational users tend to be similar for most substances and for both males and females. The only significant jump between these two seems to be for over-the-counter (OTC) use, in which multi-purpose users are significantly more likely to be using, and for marijuana use among females. Otherwise, recreational and multi-purpose users are consistently and significantly more likely to be using various substances, including cigarettes, alcohol, marijuana, hallucinogens, inhalants, cocaine, street uppers, and ecstasy, in comparison to medical users. Heroin was the only substance for which there is not consistent significance across motivations, likely due to its very uncommon use. All three categories of prescription drug users are consistently more likely to be using substances than the general population. However, medical users are typically closer to the normal prevalence rate than the other motivation groups, and are even statistically equal to the general population for the more hardcore drugs.

Table 3: Risk and deviant behaviors by motivation and gender (percentages)

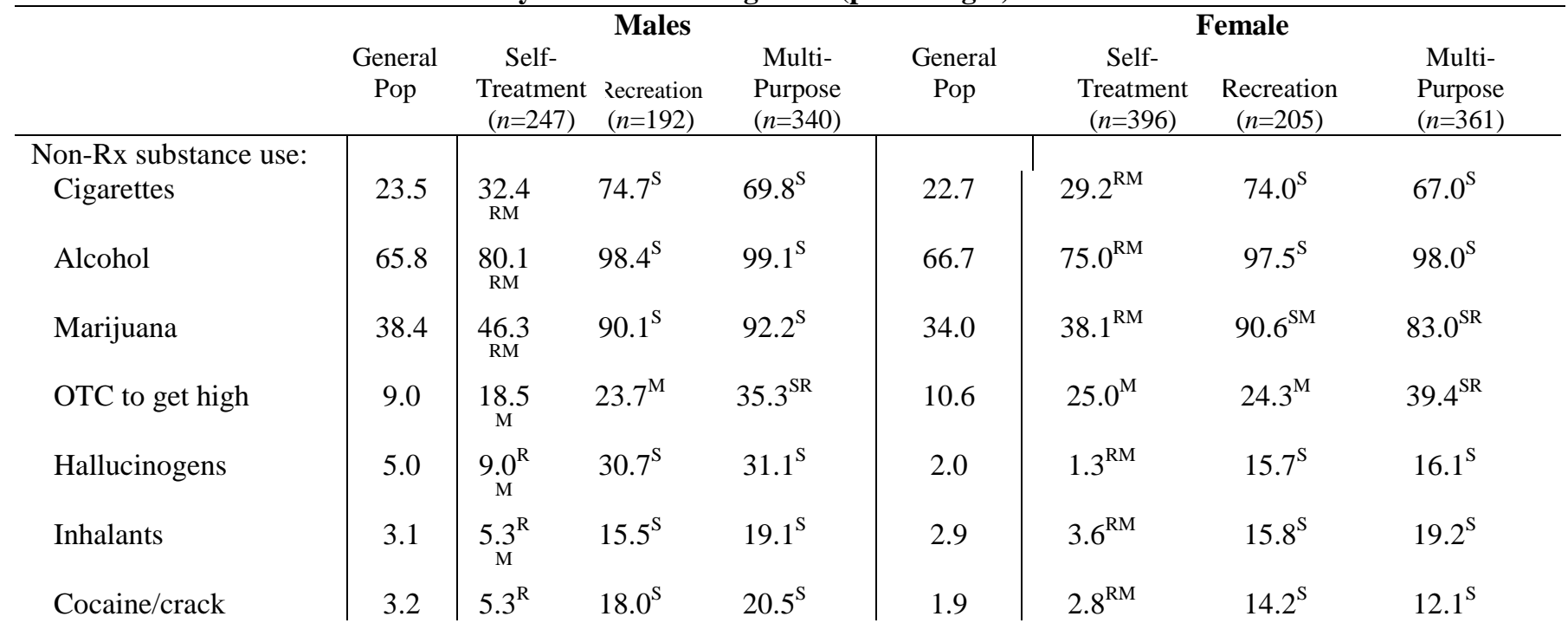


International Journal of Child, Youth and Family Studies (2013) 2: 245-258

\begin{tabular}{|c|c|c|c|c|c|c|c|c|}
\hline \multicolumn{9}{|c|}{$M$} \\
\hline Street uppers & 1.9 & $0.8^{\mathrm{R}}$ & $13.8^{\mathrm{S}}$ & $15.7^{\mathrm{S}}$ & 1.8 & $2.3^{\mathrm{RM}}$ & $13.7^{\mathrm{S}}$ & $13.0^{\mathrm{S}}$ \\
\hline Ecstasy & 1.7 & $2.9^{\mathrm{M}}$ & 6.3 & $10.7^{\mathrm{S}}$ & 1.2 & $1.8^{\mathrm{RM}}$ & $7.3^{\mathrm{s}}$ & $8.5^{\mathrm{s}}$ \\
\hline Heroin & 0.8 & $0.8^{\mathrm{M}}$ & 2.1 & $3.7^{\mathrm{S}}$ & 0.2 & 0.5 & 0.5 & 1.7 \\
\hline \multicolumn{9}{|l|}{ Non-violent deviance: } \\
\hline Cheated on test & 55.5 & $\begin{array}{c}65.8 \\
\mathrm{RM}\end{array}$ & $80.0^{\mathrm{S}}$ & $76.8^{\mathrm{S}}$ & 49.6 & $57.7^{\mathrm{RM}}$ & $70.3^{S}$ & $68.3^{\mathrm{S}}$ \\
\hline Shoplifted & 23.0 & $\begin{array}{c}30.1 \\
\mathrm{RM}\end{array}$ & $54.2^{\mathrm{S}}$ & $55.8^{\mathrm{S}}$ & 15.5 & $19.8^{\mathrm{RM}}$ & $46.3^{S}$ & $40.4^{\mathrm{S}}$ \\
\hline Vandalized Property & 29.7 & $\begin{array}{l}43.9 \\
\mathrm{RM}\end{array}$ & $58.7^{\mathrm{S}}$ & $60.9^{\mathrm{S}}$ & 10.9 & $16.2^{\mathrm{RM}}$ & $28.2^{\mathrm{S}}$ & $36.0^{\mathrm{S}}$ \\
\hline \multicolumn{9}{|l|}{ Violent deviance: } \\
\hline Carry weapon & 22.2 & 32.5 & $40.2^{\mathrm{M}}$ & $53.7^{\mathrm{SR}}$ & 6.4 & $11.9^{\mathrm{M}}$ & $9.8^{\mathrm{M}}$ & $20.3^{S R}$ \\
\hline $\begin{array}{l}\text { Take weapon to } \\
\text { school }\end{array}$ & 8.7 & $\underset{\mathrm{M}}{13.0}$ & 15.8 & $20.8^{S}$ & 3.0 & 4.9 & 4.5 & 8.1 \\
\hline Group fighting & 19.6 & $\begin{array}{c}26.1 \\
\mathrm{RM}\end{array}$ & $38.6^{\mathrm{S}}$ & $42.6^{S}$ & 8.3 & $12.8^{\mathrm{M}}$ & 16.7 & $19.2^{\mathrm{S}}$ \\
\hline Hit someone & 29.1 & $\underset{M}{45.2}$ & 51.7 & $63.4^{\mathrm{S}}$ & 19.3 & $28.2^{\mathrm{M}}$ & $27.5^{\mathrm{M}}$ & $44.9^{S R}$ \\
\hline $\begin{array}{l}\text { Other Risk Factors: } \\
\text { Skipped School }\end{array}$ & 39.0 & $\begin{array}{l}46.7 \\
\mathrm{RM}\end{array}$ & $68.9^{\mathrm{S}}$ & $74.2^{\mathrm{S}}$ & 35.1 & $43.5^{\mathrm{RM}}$ & $65.4^{\mathrm{S}}$ & $68.7^{\mathrm{S}}$ \\
\hline Suspended / Expelled & 13.7 & $\underset{\mathrm{RM}}{15.4}$ & $32.1^{\mathrm{S}}$ & $29.8^{\mathrm{S}}$ & 8.1 & $9.6^{\mathrm{RM}}$ & $18.0^{\mathrm{S}}$ & $18.9^{\mathrm{S}}$ \\
\hline Gang Membership & 7.5 & $9.6^{\mathrm{M}}$ & 17.2 & $24.6^{\mathrm{S}}$ & 2.2 & 4.0 & 5.9 & 7.0 \\
\hline Arrested & 6.8 & $\underset{\mathrm{M}}{11.3}$ & 19.8 & $21.1^{\mathrm{S}}$ & 2.8 & $2.3^{\mathrm{RM}}$ & $7.8^{\mathrm{S}}$ & $8.2^{\mathrm{S}}$ \\
\hline
\end{tabular}

With regard to the source of prescription drugs, there is substantial variation based on the different motivations for use. Specifically, those using for medical purposes are significantly less likely to be getting the drugs from friends, at a party, or from a dealer. They are also less likely to get them from a parent without permission, though that difference is only significant for females, which is largely driven by female multi-purpose users being much more likely to be taking drugs from parents without permission. Conversely, medical only users are significantly and dramatically more likely to be getting the drugs from their parents with permission. In comparison to recreational users, male medical users are more than seven times as likely to be getting the drugs from their parents, and female medical users are more than six times as likely to have parents as their supplier. The proportions of multi-purpose users getting drugs from their parents are between these two extremes for both genders, and only significantly different from medical users indicating more similarity to recreational users. Finally, very few users report getting their non-prescribed prescription drugs over the Internet, with no significant differences found. 
On measures of non-violent deviance, similar patterns can be observed. Specifically, there are significant differences between users based on their motivation for using, in which recreational and multi-purpose users are more likely to engage in cheating, shoplifting, and vandalism than medical only users. Moreover, this appears to be true for both male and female prescription drug users, and all categories of users are more likely to be engaging in the behaviors than the general population.

For violence, recreational users are statistically similar to medical users unlike for other indicators. However, individuals with multiple motivations are again significantly more likely to engage in each type of behavior, with one exceptions based on gender. Specifically, there are no significant differences for taking a weapon to school for females. Otherwise, multi-purpose users are consistently and significantly at higher risk for violence.

The final area of analysis involves risk factors potentially related to using prescription drugs without a prescription. As with most previous analyses, the results here indicate that recreational and multi-purpose users are more likely to report having skipped school, been suspended or expelled, belong to a gang, or been arrested. These differences by motivation are all significant, except for arrest among males and gang membership among females. In comparison to the general population, medical users are only marginally more likely to report having engaged in or experienced these potentially related risk factors.

\section{Discussion}

With prescription drug abuse stable but historically high among American youth (Johnston et al., 2011) and consequences on the rise (SAMHSA, 2011), it is vital to more fully understand the factors surrounding the use,of prescription drugs without a prescription and consequences arising from such use. Though prior research has paved the way for a better understanding, much remains to be fully examined. Of relevance to the present study are the under-explored motivations for using medications without a prescription. Using data from a random sample of American youth, this study examined the correlates of prescription drug abuse with an emphasis on differences based on gender and motivation for using the non-prescribed prescription drug.

The results indicated that males are more likely than females to be using non-prescribed medications for recreational purposes, while females are more likely to be using them to relieve pain. Those who were self-treating tended to be using painkillers, while the recreational users were likely to be using multiple types of prescription drugs. In terms of the sources of the drugs, peers were the most common response regardless of the motivation, but more often so for recreational users. The Internet was not a noteworthy source regardless of gender or motivation. Finally and perhaps most noteworthy, the recreational and multi-purpose users were much more likely to be engaging in other risk behaviors than the self-treaters.

Of course, it should be noted that these data come from self-report surveys. As such, it is quite possible that inaccurate or untruthful responses could be present in the data. Given the high usage rates and prevalence rates for other risk behaviors, though, it would appear that students did not shy away from reporting deviant behavior given the anonymous nature of the survey 
design. Moreover, the survey included a fake-drug to screen out dishonest participants ${ }^{2}$ and also is checked for inconsistent answers. Though the possibility of dishonesty remains, it seems unlikely to be a pervasive or noteworthy problem. There is also a bias in the statistics presented here, as students who drop out of high school are not included in the sample. Though this may result in underestimating the population statistics, it does not undermine the validity of the comparisons across groups by motivation.

These findings, particularly those relating to risk behaviors connected to prescription drug abuse suggest that recreational and multi-purpose users are the youth at greatest risk. To be sure, self-treating youth are, indeed, more likely to engage in risk behaviors than the general youth population. Moreover, their use is still illegal and could result in negative medical outcomes. Nevertheless, their increased risk of engaging in the behaviors studied here pales in comparison to the differences for those with recreational use at least partially in mind.

The implications of these findings are twofold. First, policy creators and those engaged with youth should note the distinct differences in the motivations for use. Though both recreational and self-treating uses are prohibited and troubling, the former is more strongly related to other risks. Thus, different strategies should be used when addressing drug problems with youth depending on the motivation involved. Second, future research should similarly take these implications into account and design studies that recognize the differences by motivation. Recreational use and self-treating use have distinct correlates and consequences, and should not be treated as the same category of use. Benefit would also be gained from a more in-depth analysis of the causes and predictors of prescription drug abuse with an emphasis on the differing motivations.

\footnotetext{
${ }^{2}$ Less than one percent of the sample is lost through this, and these cases are not included in the response rate calculation (i.e., they are considered non-valid responses and treated the same as if no response were provided).
} 
International Journal of Child, Youth and Family Studies (2013) 2: 245-258

\section{References}

Boyd, C. J., McCabe, S. E., Cranford, J. A., \& Young, A. (2006). Adolescents’ motivations to abuse prescription medications. Pediatrics, 118(6), 2472-2480.

Boyd, C. J., McCabe, S. E., \& Teter, C. J. (2006). Medical and nonmedical use of prescription pain medications by youth in a Detroit-area public school district. Drug and Alcohol Dependence, 81(1), 37-45.

Boyd, C. J., Young, A., Grey, M., \& McCabe, S. E. (2009). Adolescents' nonmedical use of prescription medications and other problem behaviors. Journal of Adolescent Health, 45(6), 543-550.

Herman-Stahl, M. A., Krebs, C. P., Kroutil, L. A., \& Heller, D. C. (2006). Risk and protective factors for nonmedical use of prescription stimulants and methamphetamine among adolescents. Journal of Adolescent Health, 39(3), 374-380.

Johnston, L. D., O'Malley, P. M., Bachman, J. G., \& Schulenberg, J. E. (2011, December 14). Marijuana use continues to rise among U.S. teens, while alcohol use hits historic lows. Ann Arbor, MI: University of Michigan News Service. Retrieved from: http://www.monitoringthefuture.org/pressreleases/11drugpr.pdf

Levine, S. B., \& Coupey, S. M. (2009). Nonmedical use of prescription medications: An emerging risk behavior among rural adolescents. Journal of Adolescent Health, 44(4), 407-409.

McCabe, S. E., Boyd, C. J., \& Teter, C. J. (2005). Illicit use of opioid analgesics by high school seniors. Journal of Substance Abuse Treatment, 28(3), 225-230.

McCabe, S. E., Boyd, C. J., \& Young, A. (2007). Medical and nonmedical use of prescription drugs among secondary school students. Journal of Adolescent Health, 40(1), 76-83.

McCabe, S. E., Teter, C. J., \& Boyd, C. J. (2004). The use, misuse and diversion of prescription stimulants among middle and high school students. Substance Use \& Misuse, 39(7), 1095-1116.

Poulin, C. (2001). Medical and nonmedical stimulant use among adolescents: From sanctioned to unsanctioned use. Canadian Medical Association Journal, 165(8), 1039-1044.

Schepis, T. S., \& Krishnan-Sarin, S. (2009). Sources of prescriptions for misuse by adolescents: Differences in sex, ethnicity, and severity of misuse in a population-based study. Journal of the American Academy of Child and Adolescent Psychiatry, 48(8), 828-836. 
International Journal of Child, Youth and Family Studies (2013) 2: 245-258

Substance Abuse and Mental Health Services Administration. (2011). Drug abuse warning network, 2008: National estimates of drug-related emergency department visits. Retrieved from: http://www.samhsa.gov/data/2k11/DAWN/ED/DAWN2k8ED.pdf

Zacny, J., Bigelow, G., Compton, P., Foley, K., Iguchi, M., \& Sannerud, C. (2003). College on problems of drug dependence task force on prescription opioid nonmedical use and abuse: Position statement. Drug and Alcohol Dependence, 69(3), 215-232 
International Journal of Child, Youth and Family Studies (2013) 2: 245-258 